* Pós-Doutor em Direito Constitucional pela Universidade de Lisboa, Doutor e Mestre em Direito pela PUC/SP, Professor do Mestrado e da Graduação em Direito da Uninter, e da Graduação da UniSociesc, Professor convidado do Catedrático Jorge Miranda nos Cursos de Doutorado, Mestrado e Licenciatura em Direito nas Universidades de Lisboa e Católica Portuguesa. Diretor de Relações Internacionais do InstitutodeDireito Constitucional e Cidadania. Autor das editoras Forense, Lumen Juris, Fórum e InterSaberes, Tradutor francêsportuguês-francês e inglêsportuguês-inglês. Palestrante e organizador de eventos na Université Paris 1 Sorbonne juntamente com o Catedrático Otto Pfersmann.

\footnotetext{
**Especialista em Direito Constitucional Contemporâneo, pelo Instituto Constitucional Contemporâneo Brasileiro; Especialista em Direito Público e Privado pela Escola do Ministério Público - FEMPAR; Graduada em Direito, pela Universidade Estadual de Londrina - UEL; Servidora Pública do Município de Londrina/PR; Advogada no Paraná, Brasil.
}

\section{A Efetividade Dos Direitos Humanos E A JURISPRUdênCIA DA CORTE InTERAMERICANA DE Direitos Humanos}

\author{
The Effectiveness Of Human Rights And The \\ JurisPrudence Of The INTER-AmERICAN COURT OF \\ Human Rights
}

Como citar: PAGLIARINI, Alexandre Coutinho; GÉLIO, Graciele. A EFETIVIDADE DOS DIREITOS HUMANOS E A JURISPRUDÊNCIA DA CORTE INTERAMERICANA DE DIREITOS HUMANOS. Revista do Instituto de Direito Constitucional e Cidadania - IDCC, Londrina, v. 4, n. 2, p 10-31, dez, 2019. ISSN: 2596-0075.

https://doi.org/10.48159/revistadoidcc.v4n2.pagliarini.gelio

Resumo: O objeto do presente trabalho visa analisar a efetividade dos direitos humanos através das decisões internacionais emitidas pela Corte Interamericana de Direitos Humanos, por meio de uma breve leitura do sistema interamericano de proteção de direitos humanos e seus conjuntos de procedimentos previstos na Carta da Organização dos Estados Americanos e na Convenção Americana sobre Direitos Humanos, bem como analisar a jurisprudência da Corte em dois casos, de diferentes datas, em que o Brasil foi condenado, que caracterizam a jurisprudência da Corte. Cabe ainda ao presente, apontar o impacto positivo e negativo das sentenças analisadas, bem como as dificuldades para sua aplicação e revelar medidas que possibilitem a efetividade e aplicação dos direitos humanos.

Palavras chave: Direitos humanos. Corte Interamericana de Direitos Humanos.

Abstract: The paper's purpose is to analyze the effectiveness of human rights through the international decisions issued by the Inter-American Court of Human Rights, through a brief reading of the inter-American system for the protection of human rights and its sets of procedures provided for in the Charter of the Organization of American States American Convention and the American Convention on Human Rights, as well to analyze decisions of two different cases of the Court in which Brazil 
was convicted to point out positive and negative impact of the sentences analyzed, as well as the difficulties for its application and to reveal measures that make possible the effectiveness and application of human rights.

Keywords: Human rights. Inter-American Court of Human Rights. 


\section{INTRODUÇÃO}

O presente projeto tem por finalidade analisar a efetividade dos direitos humanos através das decisões internacionais emitidas pela Corte Interamericana de Direitos Humanos.

O estudo de direitos do homem no campo global revela o interesse dos órgãos de direitos humanos internacionais, que por meio de uma estrutura de mecanismos e procedimentos complexos, estabelece um sistema protetivo de direitos humanos, primeiramente buscando seu fortalecimento nacional e, por conseguinte, zelam pelo não retrocesso no sistema de proteção de direitos.

Para a compreensão acerca dos mecanismos e sistema de proteção dos direitos humanos é necessária uma breve leitura sobre a Carta da Organização dos Estados Americanos - OEA, Declaração Americana dos Direitos e Deveres do Homem, Convenção Americana sobre Direitos Humanos - CADH, seguida de uma maior atenção à Corte Interamericana de Direitos Humanos.

A análise da jurisprudência da Corte Interamericana possibilita a verificação quanto à aplicação dos direitos humanos de forma regionalizada, ao serem destacadas algumas das decisões e sentenças em que o Brasil foi condenado por violação aos direitos humanos. A importância do estudo das decisões internacionais em casos em que o Brasil foi condenado possibilita a verificação do impacto positivo dessas sentenças e a constatação das modificações trazidas aos direitos humanos no Brasil, bem como permite averiguar as dificuldades da aplicação das decisões da Corte em território nacional, ressaltando a resistência dos agentes políticos em aplicar o direito internacional no direito brasileiro.

Por fim, busca-se apresentar medidas praticas a serem implementadas visando à garantia de aplicação e efetividade dos direitos humanos, através do cumprimento das decisões internacionais da corte interamericana.

\section{DIREITOS HUMANOS E O SISTEMA PROTETIVO INTERAMERICANO DE DIREITOS HUMANOS}

O estudo dos direitos humanos e a questão da efetividade deles são de grande relevância ao mundo jurídico, assim como a melhor compreensão acerca dos órgãos internacionais de proteção de direitos fundamentais e da dignidade da pessoa humana.

Através das conquistas históricas que culminaram na existência da Carta da Organização dos Estados Americanos - OEA, Declaração Americana dos Direitos e Deveres do Homem e Convenção Americana sobre Direitos Humanos-CADH, os direitos defendidos internacionalmente se fortaleceram, criando o sistema protetivo interamericano de direitos humanos.

\subsection{Conceito de Direitos Humanos}


Os direitos humanos versam sobre garantias previstas em tratados internacionais, que revelam o caráter indispensável para a existência digna do individuo, que se aperfeiçoa no ordenamento jurídico de um determinado Estado, tornando-se norma de direito fundamental, reconhecida pela Constituição.

Nesse sentido o Doutor Ingo Wolfgang Sarlet diferencia o conceito de direitos humanos e direitos fundamentais, definindo o primeiro como aquele que guardaria relação com os documentos de direito internacional:

Em que pese sejam ambos os termos ('direitos humanos'e 'direitos fundamentais') comumente utilizados como sinônimos, a explicação corriqueira e, diga-se de passagem, procedente para a distinção é de que o termo 'direitos fundamentais' se aplica para aqueles direitos do ser humano reconhecidos e positivados na esfera do direito constitucional positivo de determinado Estado, ao passo que a expressão 'direitos humanos' guardaria relação com os documentos de direito internacional, por referir-se àquelas posições jurídicas que se reconhecem ao ser humano como tal, independentemente de sua vinculação com determinada ordem constitucional, e que, portanto, aspiram à validade universal para todos os povos e tempos, de tal sorte que revelam um inequívoco caráter supranacional (internacional) ${ }^{1}$

Para a Professora Dra. Eleonora Mesquita $\mathrm{Ceia}^{2}$, qualquer meio de proteção de direitos humanos internacional busca defender e fortalecer a garantia desses direitos em plano nacional e também age como instrumento de prevenção ao retrocesso no sistema de proteção. Acredita que os objetivos estão interligados, uma vez que fortalecendo a tutela dos direitos humanos em um Estado, todos os demais direitos também serão defendidos.

\subsection{A Carta da OEA}

A Carta da Organização dos Estados Americanos foi aprovada em 30 de abril de 1948, entrando em vigência em 1951. Ela representa um organismo regional dentro das Nações Unidas, mas que é independente.

A Carta da OEA apresenta os direitos humanos impondo a obrigação de fazer, isto é, apresentando a sua obrigatoriedade. Enquanto a Carta da ONU dispõe acerca do dever dos Estados em respeitar os direitos humanos, sendo uma obrigação de não-fazer, conforme explica Prof ${ }^{a}$ Dra. $^{a}$ Theresa Rachel Couto Correia ${ }^{3}$.

A Carta da OEA encontra-se divida em três partes, sendo a primeira sobre os princípios e demais definições jurídicas, a segunda fixa os órgãos, competências e funções e a terceira as

1 SARLET, Ingo Wolfgang. A eficácia dos direitos fundamentais. 6. ed. Porto Alegre: Livraria do Advogado, 2006. p. 36.

2 CEIA, Eleonora Mesquita. A jurisprudência da Corte Interamericana de Direitos Humanos e o desenvolvimento da proteção dos direitos humanos no Brasil. Revista Emerj, Rio de Janeiro, v. 16, n. 61, p. 113-152, jan./mar. 2013. p. 113. Disponível em: http://www.emerj.tjrj.jus.br/revistaemerj_online/edicoes/revista61/revista61_113.pdf. Acesso em: 5 dez. 2017.

3 CORREIA, Theresa Rachel Couto. Corte Interamericana de Direitos Humanos. Curitiba: Juruá Editora, 2008. p. 96. 
disposições gerais e transitórias.

\subsection{A Declaração Americana dos Direitos e Deveres do Homem}

A Declaração Americana surgiu após já existirem diversas outras convenções não menos importantes que essa. Nela consta a afirmação de que os direitos humanos são inerentes à pessoa humana, assim como os direitos civis, políticos, sociais e culturais.

Através da Declaração Americana, os Estados tiveram uma melhor compreensão acerca da Carta da OEA, o que serviu como fundamento para a Comissão Interamericana de Direitos Humanos.

Seguindo o entendimento jurisprudencial do Tribunal Interamericano, os direitos garantidos na Declaração Universal, bem como na Declaração Americana já integram o direito consuetudinário, sendo-os erga omnes, o que gera em caso de violação a responsabilidade internacional por todos os Estados-membros da OEA.

\subsection{A Convenção Americana sobre Direitos Humanos}

A Convenção Americana sobre Direitos Humanos, conhecida como Pacto de San José, foi adotada na Conferência Especializada Interamericana sobre Direitos Humanos em 1969, entrando em vigor em 1978, sendo o mecanismo de maior relevância perante o sistema interamericano de direitos humanos. ${ }^{4}$ Nela constam reconhecidos diversos direitos civis, políticos, inclusive sociais, econômicos e culturais, sendo os três últimos acrescentados através de um protocolo adicional em 1988, chamando de Protocolo de San Salvador.

A Convenção reuniu os direitos humanos codificando o tema e estabeleceu a competência da Comissão Interamericana de Direitos Humanos e da Corte Interamericana.

A Convenção Americana assinala em seu art. $2^{\circ}$ que "os Estados comprometem-se a adotar, de acordo com suas normas constitucionais e com as disposições desta Convenção as medidas legislativas ou de outra natureza que forem necessárias para tornar efetivos tais direitos e liberdades" ". Assim, o Estado ao aderir a Convenção Americana, encontra-se obrigado a adotar em seu direito interno, os meios necessários para cumprir as obrigações assumidas. Conforme cita Correia:

Além disso, ao aderir à Convenção e reconhecer a competência da Corte Interamericana de Direitos Humanos, assume também um compromisso transcendente aos limites do poder soberano interno, qual seja, o de cumprir com as decisões de um órgão jurisdicional não sujeito à sua soberania. Nesta hipótese, supera-se, de forma irreversível, o dogma da soberania absoluta. Ainda assim, se restar alguma duvida, a própria Corte, na opinião consultiva 02/82,

4 BRASIL. Decreto n 678, de 6 de novembro de 1992. Promulga a Convenção Americana sobre Direitos Humanos (Pacto de São José da Costa Rica), de 22 de novembro de 1969. Brasília: Presidência da República do Brasil, 1992. Disponível em: http://www.planalto.gov.br/ccivil_03/decreto/D0678.htm. Acesso em: 20 mar. 2018.

5 Idem. 
afirmou a supremacia das normas de direito internacional de direitos humanos, independentemente de nacionalidade, bem como o principio da primazia da norma mais favorável a vitima. ${ }^{6}$

Outros dois pontos de destaque são, primeiramente, que a Convenção é expressa quanto sua adesão à democracia representativa que a torna indispensável para aplicação dos direitos humanos. Em segundo, o art. 30 da Convenção que afirma que só restrições permitidas de acordo com a Convenção serão admitidas, respeitando os direitos e liberdades nela reconhecidas, não podendo ser aplicadas, senão de acordo com as leis que atendam ao interesse geral.

\section{CORTE INTERAMERICANA DE DIREITOS HUMANOS}

O Estatuto da Corte Interamericana de Direitos Humanos em seu art. $1^{\circ}$ dispõe:

A Corte Interamericana de Direitos humanos é uma instituição judiciária autônoma cujo objetivo é a aplicação e a interpretação da Convenção Americana sobre Direitos Humanos. A Corte exerce suas funções em conformidade com as disposições da citada Convenção e deste Estatuto?.

Segundo o entendimento da Dra. Theresa Rachel Couto Correia ${ }^{8}$, a Corte IDH é independente e autônoma justamente por não depender da Organização dos Estados Americanos, o que lhe confere características específicas.

\subsection{Características Gerais}

$\mathrm{O}$ art. 33 da Convenção Interamericana de Direitos Humanos dispõe acerca de dois órgãos competentes para conhecer de assuntos relacionados ao cumprimento dos compromissos assumidos pelos Estados-partes na Convenção, sendo a Comissão Interamericana de Direitos Humanos - Comissão e a Corte Interamericana de Direitos Humanos - Corte.

A Comissão é uma entidade autônoma, que representa os membros da OEA, sendo sua competência mais ampla do que a da Corte, podendo atuar de ofício e ainda a adotar medidas a fim de contribuir para consciência dos direitos humanos.

A Comissão é composta por sete membros de alta autoridade moral e notório conhecimento sobre direitos humanos. A indicação é feita através de lista proposta pelos governos dos Estadosmembros, que podem indicar dentre seus nacionais ou de outro Estado-membro, sendo que no mínimo um deles deverá ser nacional do Estado proponente. O mandato será de quatro anos, podendo ser reeleito uma única vez. Não poderá haver mais de um nacional de um mesmo país na

6 CORREIÃ, 2008, p. 102.

7 COMISSÃO INTERAMERICANA DE DIREITOS HUMANOS. Estatuto da Corte Interamericana de Direitos Humanos. La Paz: CIDH, 1989. Disponível em: https://cidh.oas.org/Basicos/Portugues/v. Estatuto.Corte.htm. Acesso em: 20 mar. 2018.

8 CORREIA, 2008, p. 117. 


\section{Comissão.}

É função da Comissão promover a observância e defesa dos direitos humanos através do estimulo a consciência acerca dos direitos do homem; formular recomendações aos governos dos Estados-membros; preparar estudos e relatórios para o desempenho da função; solicitar aos governos dos Estados-membros informações sobre as medidas adotadas em matérias de direitos humanos; atender a consultas formuladas pelos Estados-membros, dentre outras.

Qualquer pessoa, grupo ou entidade não governamental poderá apresentar petição à Comissão contendo denuncia ou queixa de violação de direitos previstos na Convenção Interamericana de Direitos Humanos contra um Estado-membro. Inclusive um próprio Estadomembro poderá comunicar violação por parte de outro Estado-membro a direito previsto na Convenção.

Recebida a petição ou o comunicado, a Comissão verificará sua admissibilidade e solicitará ao governo do Estado apontado como infrator que preste informação no prazo estipulado pela Comissão. A Comissão fará o que entender pertinente em cada caso, pois não havendo razão para o prosseguimento da petição ou comunicação esta será arquivada, ou ainda inadmitida ou declarada improcedente, porém permanecendo, a Comissão poderá promover diligencias que entender necessárias para resolução do caso, inclusive a investigação no território onde se alegue a violação, havendo urgência e gravidade no caso, através de consentimento prévio do Estado.

Não havendo solução amistosa, a Comissão fará um relatório que será encaminhado aos Estados interessados. Se no prazo de três meses o caso não houver sido solucionado ou submetido à Corte, a Comissão poderá emitir, pelo voto da maioria absoluta dos seus membros, sua opinião e conclusões sobre a questão submetida à sua consideração, fazendo as recomendações necessárias e fixará prazo para cumprimento das medidas. Transcorrido o prazo sem a situação ser remediada, a Comissão decidirá, pelo voto da maioria absoluta dos seus membros, se o Estado tomou ou não as medidas adequadas e se publica ou não seu relatório.

Finalmente, quanto à Corte Interamericana de Direitos Humanos, esta também é composta por sete juízes, nacionais dos Estados-membros, de alta autoridade moral, juristas e de reconhecido saber acerca das matérias de direitos humanos, a fim de tratar das mais elevadas funções judiciais. Os juízes serão eleitos em votação secreta, por maioria absoluta dos Estados-partes na Convenção, tendo sido indicados através de lista apresentada pelos Estados-membros. Cada Estado-parte deverá indicar no mínimo um nacional em sua lista, podendo indicar os demais de outro Estadomembro. O mandato terá duração de seis anos, cabendo reeleição por uma única vez.

Uma das garantias ao processo é de que o juiz que já tiver tomado conhecimento do caso e encontrando-se o processo em fase de sentença, não será substituído o caso para um novo juiz eleito.

Outra característica da Corte é a permissão de juiz ad hoc, tendo em vista que sendo um dos juízes chamados ao processo, nacional de algum Estado-parte submetido à Corte, o outro Estado-parte poderá designar uma pessoa de sua escolha para integrar a Corte, na qualidade de juiz ad hoc. Se dentre os juízes chamados nenhum deles for da nacionalidade dos Estados-partes, cada 
um deles poderá indicar um juiz ad hoc. Essa possibilidade é amplamente criticada na doutrina que identifica a nomeação ad hoc, como forte tendência a tumultuar o regular andamento do processo.

O quórum para as deliberações da Corte é de cinco juízes e a Comissão aparecerá em todos os casos perante a Corte.

Quanto ao funcionamento e a sede da Corte, esta fica em San José na Costa Rica, podendo ser realizadas reuniões da OEA em qualquer Estado-membro, sendo os idiomas de trabalho o espanhol, francês, inglês e português. As reuniões ocorrem ordinariamente ou extraordinariamente. Já a secretaria é permanente sendo composta pelo Secretario e mais quatro advogados, e funciona sob a autoridade imediata do Secretario, que é nomeado pela Corte e tem dedicação exclusiva a ela. Já a equipe de advogados da secretaria é nomeada pelo Secretário-Geral da OEA em consulta ao Secretário da Corte.

No tocante às competências da Corte e suas funções, somente os Estados-partes e a Comissão tem o direito de submeter um determinado caso à Corte.

A Corte tem competência para conhecer de qualquer caso relativo à interpretação das disposições da Convenção, desde que os Estados-partes tenham reconhecido essa competência, nos termos da Convenção.

Havendo violação de direito protegido pela Convenção, a Corte determinará o direito ou liberdade do prejudicado, bem como a reparação de suas consequências. Nos casos graves e urgentes, a Corte poderá tomar medidas provisórias, inclusive nesses casos, a pedido da própria Comissão, quando o processo ainda não houver sido submetido à Corte.

A Corte Interamericana também exerce a função consultiva, pois os Estados-membros poderão consultar ela sobre a interpretação da Convenção ou outros tratados pertinentes.

No que diz respeito à parte procedimental, a sentença da Corte deverá ser fundamentada, sendo definitiva e inapelável. Havendo duvidas quanto à divergência ou alcance da sentença, o pedido de esclarecimento das partes, deve ser apresentado à Corte dentro de noventa dias da notificação da sentença.

É sabido que aos Estados-partes existe o deve de cumprir a decisão da Corte nos casos em que forem partes.

\subsection{Análise Quanto à Efetividade dos Direitos Humanos nas Decisões da Corte Interamericana}

Das decisões emanadas pela Corte Interamericana de Direitos Humanos é possível verificar o grau altíssimo de relevância frente ao cenário mundial e a importância em proteger os direitos do homem a fim de ser preservada a dignidade da pessoa humana.

Para a Prof ${ }^{a}$ Dra. Eleonora Mesquita Ceia ${ }^{9}$, qualquer meio de proteção de direitos humanos internacional busca defender e fortalecer a garantia desses direitos em plano nacional e também age como instrumento de prevenção ao retrocesso no sistema de proteção de direitos.

Através da jurisprudência da Corte, torna-se possível verificar o grau de efetividade dos

9 CEIA, 2013, p. 113. 
direitos humanos no Brasil, ao serem analisadas as decisões em casos em que o país foi condenado por violação de direitos humanos, o que torna possível verificar em casos concretos a aplicabilidade desses direitos, assim como seus pontos positivos e também negativos.

Importante ressaltar que a Corte não é um tribunal penal, não substituindo as ações penais concernentes ás violações cometidas, mas apenas julga o Estado violador com base nas violações ao direito contido na Convenção.

No entendimento da Prof ${ }^{a}$ Dra. Theresa Rachel Couto Correia ${ }^{10}$, apesar da Corte ser uma instância judicial, suas sentenças não são punitivas, pois procuram garantir ações corretivas para as falhas do sistema jurisdicional nacional. Em geral, a correção aplicada pela Corte tem sido a sobreposição de indenização às vitima ou familiares.

No presente trabalho, serão verificadas algumas decisões da Corte em períodos diversos, em casos em que o Estado brasileiro foi condenado por violação aos direitos humanos, dentre eles serão citados os casos Gomes Lund de $2010^{11}$ e Cosme Rosa Genoveva, Evandro de Oliveira ${ }^{12}$ e outros (Favela Nova Brasília) de $2015^{13}$.

\subsubsection{O caso Gomes Lund e outros (Guerrilha do Araguaia)}

$\mathrm{O}$ caso Gomes Lund foi submetido à Corte Interamericana de Direitos Humanos pela Comissão Interamericana, ante o desaparecimento forçado de 70 pessoas, membros do Partido Comunista do Brasil - PCdoB, além de outros camponeses da região como resultado de operações do exército brasileiro que dentre os anos de 1972 a 1975 não mediram esforços para acabar com a Guerrilha do Araguaia.

Entre 1964 a 1985 o Brasil estava vivenciando o período de ditatura militar e nesse contexto foi promulgada a Lei $n^{0} 6.683 / 79$ - Lei de Anistia, que encerrou uma investigação penal que tinha o escopo de julgar os responsáveis pelo desaparecimento forçado de 70 vítimas, além da execução extrajudicial da Sra. Maria Lucia Petit da Silva, cujos restos mortais foram encontrados em 14 de maio de 1996.

Os meios utilizados a fim de obter informações sobre os fatos que realmente aconteceram, não conseguiram garantir aos familiares dos desaparecidos o devido acesso à informação. Além das medidas legislativas e administrativas adotadas pelo Estado que restringiam o direito de acesso à informação dos familiares.

A Comissão solicitou à Corte a responsabilização internacional do Estado brasileiro, pelo não cumprimento e violação dos direitos de reconhecimento da personalidade jurídica, direito à vida, integridade pessoal, liberdade pessoal, garantias judiciais, liberdade de pensamento e

10 CORREIA, 2008, p. 132.

11 COMISSÃO INTERAMERICANA DE DIREITOS HUMANOS. Caso Gomes Lund e outros ("Guerrilha do Araguaia") Vs. Brasil. Exceções Preliminares, Mérito, Reparações e Custas. Brasil, 24 de novembro de 2010. Serie C No. 219.

12 COMISSÃO INTERAMERICANA DE DIREITOS HUMANOS. Relatório no 141/11. Mérito. Caso 11.566 e 11.694. Mérito. Cosme Rosa Genoveva, Evandro de Oliveira e outros (Favela Nova Brasília), Brasil, 31 de outubro de 2011. Disponível em: https://sidh.cejil.org/es/document/mdpk7vb6auugposd81knpnwmi. Acesso em: 20 mar. 2018.

13 COMISSÃO INTERAMERICANA DE DIREITOS HUMANOS. Caso Favela Nova Brasília Vs. Brasil. Interpretação da Sentença de Exceções Preliminares, Mérito, Reparações e Custas. Brasil, 5 de fevereiro de 2018. Serie C N $\mathrm{N}^{\circ} .345$. 
expressão e proteção judicial da Convenção Americana sobre Direitos Humanos cumulados ao direito de obrigação geral de respeitar e garantir os direitos e dever de adotar disposições de direito interno da Convenção.

O caso teve inicio em 7 de agosto de 1995, quando a Comissão Interamericana recebeu a petição dos fatos contra o Brasil. O Estado brasileiro apresentou resposta em maio de 1996.

Em 2008 a Comissão aprovou o Relatório de Mérito concluindo que o Estado brasileiro praticou atos de tortura contra os desaparecidos membros do PCdoB e camponeses da região. Defendeu ainda, que em virtude da Lei de Anistia, o Estado não conseguiu concluir nenhuma investigação penal para julgar e sancionar os responsáveis por estes desaparecimentos forçados, além de não permitir o devido acesso à informação sobre as vitimas desaparecidas.

A Comissão recomendou ao Estado criar medidas que impeçam a Lei de Anistia de criar obstáculos para a persecução penal de violação de direitos humanos; determinar, na jurisdição comum, a responsabilidade penal pelo desaparecimento forçado das vítimas; realizar as ações necessárias a fim de sistematizar e publicar todos os documentos relacionados com as operações militares contra a Guerrilha do Araguaia; fortalecer os esforços já empreendidos na busca e sepultura das vítimas desaparecidas; ofertar às famílias das vitimas tratamento físico e psicológico, assim como a garantia de atos que não permitam a repetição dos delitos cometidos; implementar junto às Forças Armadas brasileiras um programa de educação em direitos humanos e tipificar o crime de desaparecimento forçado.

Em março de 2009 o Brasil apresentou um relatório em que constavam as ações implementadas, porém, a Comissão entendeu ao analisar as informações, que as medidas não foram satisfatórias nos termos do Relatório $91 / 08^{14}$, decidindo, por isso, submeter o caso à jurisdição da Corte Interamericana.

Como explica a Dra. Eleonora Mesquita Ceia ${ }^{15}$, a Corte concluiu que não há controvérsia quanto aos fatos do desaparecimento forçado, já que este constitui uma violação múltipla que se inicia com uma privação de liberdade contrária ao artigo $7^{\circ}$ da $\mathrm{CADH}$. A Corte também assevera que a falta de investigação desses acontecimentos representa uma violação à obrigação estatal de garantir a toda pessoa seu direito à vida e a inviolabilidade dela. Ressalta ainda, que o desaparecimento forçado implica na vulneração do direito ao reconhecimento da personalidade jurídica, vez que seu desaparecimento nega a existência digna de ser humano. Relata que o Brasil violou os direitos de reconhecimento da personalidade jurídica, à vida, à integridade pessoal, e à liberdade pessoal, consagrados, respectivamente, nos artigos $3^{\circ}, 4^{\circ}, 5^{\circ}$ e $7^{\circ}$, além da proteção judicial e garantias judiciais. Destaca que a Corte também afirmou que o Brasil não pode restringir o acesso à informação alegando segredo de Estado ou confidencialidade da informação.

Por unanimidade a Corte resolveu que o Brasil deve:

conduzir a investigação penal dos fatos do presente caso a fim de esclarecê-los,

14 COMISSÃO INTERAMERICANA DE DIREITOS HUMANOS. Relatório n 91/08. Caso 11.552. Mérito. Julia Gomes Lund e outros (Guerrilha do Araguaia), Brasil, 31 de outubro de 2008.

15 CEIA, 2013, p. 125. 
determinar os responsáveis e aplicar as sanções cabíveis;

(b) realizar todos os esforços com o objetivo de determinar o paradeiro das vítimas desaparecidas e, se for o caso, identificar e entregar os restos mortais a suas famílias;

(c) oferecer tratamento médico e psicológico ou psiquiátrico que as vítimas requeiram;

(d) publicar a sentença no Diário Oficial, o resumo da sentença em jornal de circulação nacional, assim como a íntegra da sentença em meio eletrônico e a publicação da mesma em forma de livro;

(e) realizar um ato público de reconhecimento de responsabilidade internacional sobre os fatos do presente caso;

(f) continuar com as ações desenvolvidas em matéria de capacitação e implementar, em um prazo razoável, um programa ou curso permanente e obrigatório sobre direitos humanos, dirigido a todos os níveis hierárquicos das Forças Armadas;

(g) tipificar o delito de desaparecimento forçado de pessoas, em conformidade com os parâmetros interamericanos.

(h) prosseguir desenvolvendo as iniciativas de busca, sistematização e publicação de toda a informação sobre a Guerrilha do Araguaia, bem como da informação relativa a violações de direitos humanos ocorridas durante o regime militar e;

(i) pagar indenização por danos morais e materiais às vítimas. ${ }^{16}$

Em 14 de dezembro de 2011, o Estado brasileiro submeteu à Corte seu relatório acerca do cumprimento da sentença do caso em apreço. Nele citou a execução de todas as determinações da Corte. Em resposta, os representantes refutaram os argumentos do Estado, informando o não cumprimento da decisão emanada pela Corte. Principalmente no que tange a propositura de ação penal no âmbito interno, vez que a mesma foi rejeitada judicialmente, com fulcro na Lei de Anistia.

A Lei de Anistia se aplica aos crimes políticos e conexos, se estendendo também aos crimes comuns praticados pelos agentes de repressão contra os opositores durante o regime militar.

Sobre o tema, a Corte decidiu por unanimidade declarar que as disposições legais brasileiras a respeito da Lei de Anistia impedem a investigação e também sanção das violações aos direitos humanos, sendo incompatível com a Convenção Americana. Declarou a responsabilidade do Estado quanto ao desaparecimento forçado e, portanto, pela violação dos direitos ao reconhecimento da personalidade jurídica, à vida, à integridade pessoal e à liberdade pessoal, estabelecidos nos artigos 3, 4, 5 e 7 da Convenção Americana sobre Direitos Humanos, em relação com o artigo 1.1 desse instrumento. Informa que o Estado descumpriu a obrigação de adequar seu direito interno à Convenção Americana sobre Direitos Humanos, sendo responsável também pela violação do direito à liberdade de pensamento e de expressão consagrado no artigo 13 da Convenção Americana sobre Direitos Humanos, em relação com os artigos 1.1, 8.1 e 25 desse instrumento.

Deve o Estado realizar todos os meios a fim de encontrar as vítimas desaparecidas e identificar os restos mortais. Oferecer tratamento médico e psicológico ou psiquiátrico que as vítimas requeiram. Reconhecer através de ato público sua responsabilidade internacional a respeito 
dos fatos do presente caso. O Estado deve continuar com as ações desenvolvidas em matéria de capacitação sobre direitos humanos nas Forças Armadas. Adotar, em um prazo razoável, as medidas que sejam necessárias para tipificar o delito de desaparecimento forçado de pessoas. Promover a sistematização e publicação de todas as informações sobre a Guerrilha do Araguaia.

O Estado brasileiro deve ainda, pagar multas, a titulo de indenização por dano material aos familiares das vitimas.

Como bem assinala a Dra. Eleonora Mesquita Ceia,

Em resumo, a sentença da Corte no caso Gomes Lund vs. Brasil representou uma significativa contribuição para ampliar o debate sobre a justiça de transição, bem como promover políticas transicionais no Brasil. Isso porque, de acordo com os princípios ou objetivos da justiça de transição, a referida sentença proporcionou: o direito de reparação às vítimas, o direito à justiça com a determinação de responsabilizar os violadores de direitos humanos e a consagração do direito à verdade e à memória, promovendo a conscientização quanto à verdade sobre as violações de direitos humanos cometidas durante o regime militar, como também à ilegitimidade dessas práticas, de forma a evitar sua repetição ${ }^{17}$

O caso representou uma oportunidade para consolidar a jurisprudência da Corte Interamericana sobre as leis de anistia quanto aos desaparecimentos forçados, bem como promoveu a valorização dos direitos humanos em casos em que houve praticas tortuosas durante o regime militar, assim como a conscientização da sociedade em relação ao tema.

\subsubsection{Cosme Rosa Genoveva, Evandro de Oliveira e outros (Favela Nova Brasília)}

Em novembro de 1995 e em julho de 1996 a Comissão Interamericana de Direitos Humanos recebeu duas petições contra o Estado brasileiro alegando que os agentes da República Federativa do Brasil, neste caso através dos oficiais da Polícia Civil do Rio de Janeiro praticaram execuções extrajudiciais e atos de abuso sexual contra supostas vítimas na Favela Nova Brasília, durante trabalhos da polícia.

De acordo com Relatório ${ }^{\mathrm{o}} 141.11^{18}$ da Comissão, os peticionários relataram que em 08 de maio de 1995 uma incursão policial realizada na Favela Nova Brasília, composta por 14 policiais civis armados adentraram a Favela com objetivo de apreender um carregamento de armas que seria entregue a um traficante de drogas local. Houve troca de tiros e de acordo com as testemunhas no mínimo 8 traficantes foram executados e 26 pessoas foram mortas, sendo Cosme Rosa Genoveva, Evandro de Oliveira e outros.

Em outra petição, afirmam que em 18 de outubro de 1994, outra incursão policial também realizada na Favela Nova Brasília, composta por cerca de 110 policiais civis, realizaram uma

17 CEIA, 2013, p. 133.

18 COMISSÃO INTERAMERICANA DE DIREITOS HUMANOS. Relatório no 141/11. Mérito. Caso 11.566 e 11.694. Mérito. Cosme Rosa Genoveva, Evandro de Oliveira e outros (Favela Nova Brasília), Brasil, 31 de outubro de 2011. Disponível em: https://sidh.cejil.org/es/document/mdpk7vb6auugposd8lknpnwmi. Acesso em: 20 mar. 2018. 
operação com objetivo de cumprir 104 mandatos de prisão contra supostos traficantes de droga. Informaram que a imprensa na época qualificou a ação como uma retaliação pelo ataque à $21^{\mathrm{a}}$ Delegacia de Polícia, que ocorreu em 15 de outubro daquele ano, deixando três policiais feridos. Relatam que alguns policiais invadiram ao mínimo de cinco casas, onde interrogaram, ameaçaram e praticaram atos de violência arbitraria e física contra algumas mulheres que se encontravam nos locais, inclusive menores de idade.

A Comissão concluiu que o Estado brasileiro é responsável por violar os direitos previstos nos artigos 4.1, 5.1, 5.2, 8.1, 11, 19 e 25.1 da Convenção Americana, em concordância com o artigo 1.1 do mesmo instrumento, assim como pela morte de 26 vítimas como resultado pelo uso excessivo da força letal pela policia, além da violação sexual e estupro.

Apresentou ao Brasil suas recomendações, sendo a realização de investigação completa e imparcial sobre os casos narrados. Adoção de meios necessários para compensar os prejuízos morais das vitimas, que sofreram violência sexual e estupro. Não denominar as mortes causadas pela policia como simples "autos de resistência". Contribuir para eliminar a impunidade policial, zelando pelas leis internas e regulamentos dessa instituição. Criar meios e sistemas que monitorem as forças de segurança quando essas fizerem uso de força letal, assim como quando souberem da pratica de violência sexual. Garantir a melhoria e profissionalização das forças policiais, incluindo treinamento para assegurar o tratamento devido a pessoas vulneráveis, como crianças, idosos, mulheres e inclusive os moradores de favela, que já sofrem preconceito por serem pobres e viverem em um local onde é predominante o crime organizado.

A Comissão decidiu submeter o caso à Corte, tendo em vista que após a comunicação do Relatório e recomendações da CIDH em 19 de janeiro de 2012, o Estado brasileiro mesmo após doze prorrogações para dar cumprimento ao recomendado, não obteve avanço significativo no caso. E ainda, o Estado deixou prescrever a maior parte das ações penais contra os agentes mencionados no Relatório, sem aplicar demais medidas para sua responsabilização.

Diante da necessidade de obtenção de justiça no caso, a Corte recebeu o processo. Após, ocorreu a notificação do Estado e representantes, seguida pela apresentação de petições, argumentos, provas e contestação. Foi realizada audiência pública em 12 e 13 de outubro de 2016, no Equador, sendo utilizado o instituto do amici curiae. Foram apresentadas alegações finais das partes em novembro de 2016 e a sentença prolatada em 16 de fevereiro de 2017.

Conforme sentença da Corte, esta decidiu pela responsabilidade internacional do Estado brasileiro por violação do direito às garantias judiciais de independência e imparcialidade da investigação; direito à proteção judicial e direito à integridade pessoal, apontando as medidas necessárias para reparação das violações dos direitos humanos.

E dispõe:

Por unanimidade, que:

9. Esta Sentença constitui, per se, uma forma de reparação.

10. O Estado deverá conduzir eficazmente a investigação em curso sobre os fatos relacionados às mortes ocorridas na incursão de 1994, com a devida 
diligência e em prazo razoável, para identificar, processar e, caso seja pertinente, punir os responsáveis, nos termos dos parágrafos 291 e 292 da presente Sentença. A respeito das mortes ocorridas na incursão de 1995, o Estado deverá iniciar ou reativar uma investigação eficaz a respeito desses fatos, nos termos dos parágrafos 291 e 292 da presente Sentença. O Estado deverá também, por intermédio do Procurador-Geral da República do Ministério Público Federal, avaliar se os fatos referentes às incursões de 1994 e 1995 devem ser objeto de pedido de Incidente de Deslocamento de Competência, no sentido disposto no parágrafo 292 da presente Sentença.

11. O Estado deverá iniciar uma investigação eficaz a respeito dos fatos de violência sexual, no sentido disposto no parágrafo 293 da presente Sentença.

12. O Estado deverá oferecer gratuitamente, por meio de suas instituições de saúde especializadas, e de forma imediata, adequada e efetiva, o tratamento psicológico e psiquiátrico de que as vítimas necessitem, após consentimento fundamentado e pelo tempo que seja necessário, inclusive o fornecimento gratuito de medicamentos. Do mesmo modo, os tratamentos respectivos deverão ser prestados, na medida do possível, nos centros escolhidos pelas vítimas, no sentido disposto no parágrafo 296 da presente Sentença.

13. O Estado deverá proceder às publicações mencionadas no parágrafo 300 da Sentença, nos termos nela dispostos.

14. O Estado deverá realizar um ato público de reconhecimento de responsabilidade internacional, em relação aos fatos do presente caso e sua posterior investigação, durante o qual deverão ser inauguradas duas placas em memória das vítimas da presente Sentença, na praça principal da Favela Nova Brasília, no sentido disposto nos parágrafos 305 e 306 da presente Sentença.

15. O Estado deverá publicar anualmente um relatório oficial com dados relativos às mortes ocasionadas durante operações da polícia em todos os estados do país. Esse relatório deverá também conter informação atualizada anualmente sobre as investigações realizadas a respeito de cada incidente que redunde na morte de um civil ou de um policial, no sentido disposto nos parágrafos 316 e 317 da presente Sentença.

16. O Estado, no prazo de um ano contado a partir da notificação da presente Sentença, deverá estabelecer os mecanismos normativos necessários para que, na hipótese de supostas mortes, tortura ou violência sexual decorrentes de intervenção policial, em que prima facie policiais apareçam como possíveis acusados, desde a notitia criminis se delegue a investigação a um órgão independente e diferente da força pública envolvida no incidente, como uma autoridade judicial ou o Ministério Público, assistido por pessoal policial, técnico criminalístico e administrativo alheio ao órgão de segurança a que pertença o possível acusado, ou acusados, em conformidade com os parágrafos 318 e 319 da presente Sentença.

17. O Estado deverá adotar as medidas necessárias para que o Estado do Rio de Janeiro estabeleça metas e políticas de redução da letalidade e da violência policial, nos termos dos parágrafos 321 e 322 da presente Sentença.

18. O Estado deverá implementar, em prazo razoável, um programa ou curso permanente e obrigatório sobre atendimento a mulheres vítimas de estupro, destinado a todos os níveis hierárquicos das Polícias Civil e Militar do Rio de Janeiro e a funcionários de atendimento de saúde. Como parte dessa formação, deverão ser incluídas a presente Sentença, a jurisprudência da Corte Interamericana a respeito da violência sexual e tortura e as normas internacionais em matéria de atendimento de vítimas e investigação desse tipo de caso, no sentido disposto nos 
parágrafos 323 e 324 da presente Sentença.

19. O Estado deverá adotar as medidas legislativas ou de outra natureza necessárias para permitir às vítimas de delitos ou a seus familiares participar de maneira formal e efetiva da investigação de delitos conduzida pela polícia ou pelo Ministério Público, no sentido disposto no parágrafo 329 da presente Sentença.

20. O Estado deverá adotar as medidas necessárias para uniformizar a expressão "lesão corporal ou homicídio decorrente de intervenção policial" nos relatórios e investigações da polícia ou do Ministério Público em casos de mortes ou lesões provocadas por ação policial. O conceito de "oposição" ou "resistência" à ação policial deverá ser abolido, no sentido disposto nos parágrafos 333 a 335 da presente Sentença.

21. O Estado deverá pagar as quantias fixadas no parágrafo 353 da presente Sentença, a título de indenização por dano imaterial, e pelo reembolso de custas e gastos, nos termos do parágrafo 358 da presente Sentença.

22. O Estado deverá restituir ao Fundo de Assistência Jurídica às Vítimas, da Corte Interamericana de Direitos Humanos, a quantia desembolsada durante a tramitação do presente caso, nos termos do parágrafo 362 desta Sentença.

23. O Estado deverá, no prazo de um ano, contado a partir da notificação desta Sentença, apresentar ao Tribunal um relatório sobre as medidas adotadas para seu cumprimento.

24. A Corte supervisionará o cumprimento integral desta Sentença, no exercício de suas atribuições e em cumprimento de seus deveres, conforme a Convenção Americana sobre Direitos Humanos, e dará por concluído o presente caso tão $\log o$ o Estado tenha dado cabal cumprimento ao que nela se dispõe. ${ }^{19}$

A República Federativa do Brasil apresentou solicitação de interpretação de Sentenças Exceções em agosto de 2017. Conforme Relatório, a Corte se manifestou decidindo:

Por unanimidade,

1. Declarar admissíveis as solicitações de interpretação da Sentença de Exceções Preliminares, Mérito, Reparações e Custas no presente caso, interpostas pelo Estado brasileiro e pelos representantes.

2. Considerar improcedentes as solicitações de interpretação da Sentença de Exceções Preliminares, Mérito, Reparações e Custas do Estado brasileiro, no que se refere: i) à adequada representação das vítimas, nos termos do parágrafo 34; ii) à competência ratione materiae, nos termos dos parágrafos 40 a 42 ; e iii) ao tipo de juro bancário aplicável sobre o valor em mora, nos termos do parágrafo 66 .

3. Esclarecer, por meio de interpretação, a Sentença de Exceções Preliminares, Mérito, Reparações e Custas, nos termos dos parágrafos 21 a 29, 49 a 52, 57 a 59 e 64 a 65 da presente Sentença de Interpretação.

4. Solicitar à Secretaria da Corte Interamericana de Direitos Humanos que notifique da presente Sentença de Interpretação o Estado, os representantes das vítimas e a Comissão Interamericana. ${ }^{20}$

Desse modo, restou clara a intenção da Corte ao julgar o caso, pois manteve a decisão primeiramente citada, vez que o Estado brasileiro violou os direitos e garantias do homem. 


\section{MEDIDAS PARA EFETIVAÇÃO DOS DIREITOS HUMANOS.}

O estudo dos casos em que o Brasil foi condenado por violar normas que protegem os direitos humanos representa um avanço para a efetivação desses direitos e garantias, vez que através da visualização dos casos concretos é possível examinar as falhas e também identificar medidas que contribuiriam para aplicação efetiva das normas.

No entendimento da Prof ${ }^{a}$. Dra. Eleonora Mesquita Ceia ${ }^{21}$, as maiores dificuldades enfrentadas no cumprimento das decisões da Corte no direito brasileiro, encontra-se na investigação dos fatos e na responsabilização dos acusados na esfera penal. Essa dificuldade se revela a medida que percebe-se a falta de preparo e capacitação tanto para as autoridades responsáveis pelos casos, como pelos poderes envolvidos, e ainda pela falta de infraestrutura adequada ou de pessoal, além do acumulo de ações no Judiciário. Outra situação identificada seria a impossibilidade em alguns casos em responsabilizar os agentes por violações aos direitos humanos, com base na Lei de Anistia.

Assim, vislumbra-se que através da compreensão das normas de direitos humanos e seu reconhecimento como norma efetiva constitucional, bem como sua expansão aos profissionais que atuam nessa área, funcionaria como alguns dos meios para efetivar aplicação dessas normas.

\subsection{Compreensão dos Direitos Humanos como Norma Efetiva Constitucional}

É notório que os agentes e demais profissionais brasileiros tem dificuldade em compreender e utilizar as normas de direitos humanos presentes nos tratados humanísticos, bem como nas Convenções cujo Brasil ratificou. Porém, uma vez que já há o reconhecimento de que todos os tratados de direitos humanos que o Estado brasileiro ratificou, além da incorporação de normas de cunho de direitos humanos expressas na Constituição Federal, imporem ao agente brasileiro a aplicação dessas leis e normas, torna-se um absurdo jurídico a não efetividade ou a violação dessas.

Os tratados humanísticos estão pacificamente reconhecidos tanto pela doutrina, como pelo Supremo Tribunal Federal, como possuidores de caráter supralegal. No Recurso Extraordinário $\mathrm{n}^{\mathrm{o}} 466.343$ de $2008^{22}$, o STF assim compreendeu definindo a supralegalidade dos tratados internacionais que versem sobre direitos humanos, ratificados pelo Brasil antes da EC n. 45 de 2004. Já os posteriores, caso votados nos termos do $\S 3^{\circ}$ do art. $5^{\circ}$ da $\mathrm{CRFB} / 88$, teriam valor de emenda constitucional23.

A Constituição de 1988 colocou os direitos humanos no rol dos princípios fundamentais

21 CEIA, 2013, p. 134.

22 BRASIL. Supremo Tribunal Federal. Recurso Extraordinário no 466.343. Recorrente: Banco Bradesco S/A. Recorrido: Luciano Cardoso Santos. Relator: Ministro Cezar Peluso, 3 de dezembro de 2008. Disponível em: http:// redir.stf.jus.br/paginadorpub/paginador.jsp?docTP=AC\&docID=595444. Acesso em: 20 mar. 2018.

23 BRASIL. Constituição (1998). Constituição da República Federativa do Brasil. In: VADE mecum. 9. ed. São Paulo: Saraiva, 2010. 
do Estado brasileiro, o que permitiu um passo importantíssimo ao Brasil em adentrar ao sistema internacional de direitos humanos.

$\mathrm{O}$ art. $5^{\circ}$ em seu parágrafo $2^{\circ}$ da $\mathrm{CRFB} / 88$ dispõe que "os direitos e garantias expressos nesta Constituição não excluem outros decorrentes do regime e dos princípios por ela adotados, ou dos tratados internacionais que a República Federativa do Brasil seja parte”24.

Com base nesse princípio resta claro que os tratados humanísticos ratificados pelo Brasil tem status de normal constitucional, por conseguinte, sua aplicação é imediata, o que não permite sua revogação por lei ordinária.

Já no $\S 3^{\circ}$ do art. $5^{\circ}$ da CRFB/88: “Os tratados e convenções internacionais sobre direitos humanos que forem aprovados, em cada Casa do Congresso Nacional, em dois turnos, por três quintos dos votos dos respectivos membros, serão equivalentes às emendas constitucionais" 25 .

Em razão do parágrafo $3^{\circ}$, grande parte da Doutrina, assim como o STF entendem que os tratados internacionais que versam sobre direitos humanos, quando não votados nos termos do $\S$ $3^{\circ}$, tem status de norma supralegal. Porém, outra parte da Doutrina, já expande sua compreensão levando em consideração a intenção do $\S 2^{\circ}$, que prevê o caráter constitucional aos tratados humanísticos, independente deles serem ou não recebidos como Emenda à Constituição ${ }^{26}$.

Lorena De Sá Ribeiro ${ }^{27}$ em seu artigo sobre Tratados internacionais sobre Direitos Humanos e seu status constitucional, citando o ensinamento de outros autores, dispõe que um tratado internacional ratificado pelo Brasil, já é normal constitucional, porém de caráter material, uma vez que não integra propriamente dita a Constituição. Já os tratados recebidos nos termos do $\S 3^{\circ}$ do art. $5^{\circ}$ da Constituição são equivalentes a emenda constitucional, recebidos como normal formal, isto é, integrando o texto constitucional.

O ilustre jurista Luigi Ferrajoli28, em um de seus livros explica sobre a soberania no mundo moderno e a crise no Estado nacional. Diz que "repensar o Estado em suas relações externas à luz do atual direito internacional não é diferente de pensar o Estado em sua dimensão interna à luz do direito constitucional.”. Explica que situações de massacres, guerras, opressões de liberdade, condições de miséria, dentre outros, não podem ser vistas apenas como males naturais ou simples injustiças, muito menos como obrigações utópicas de moral ou politica, mas devem ser reconhecidas como violações jurídicas em plano internacional.

Assim, a compreensão dos tratados humanísticos como normal constitucional pela maior parte da doutrina, bem como pela jurisprudência contribuiria para sua melhor aplicação.

24 BRASIL, 2010, p. 9.

25 Ibidem, p. 9

26 Ibidem.

27 RIBEIRO, Lorena de Sá. Tratados internacionais sobre Direitos Humanos e seu status constitucional. Brasília, 2010. Disponível em: http://www.conteudojuridico.com.br/artigo,tratados-internacionais-sobre-direitos-humanose-seu-status-constitucional,28863.html. Acesso em: 20 mar. 2018.

28 FERRAJOLI, Luigi. A soberania no mundo moderno: nascimento e crise do Estado nacional. São Paulo: Martins Fontes, 2002. 


\subsection{Expansão do Direito Internacional e Direitos Humanos aos Profissionais da Área}

No tocante à aplicação das normas de direitos humanos, o despreparo dos agentes que trabalham diretamente com essas é imenso. Em parte, isso acontece por desconhecimento.

Novamente a Prof ${ }^{\mathrm{a}}$ Dra. Eleonora Mesquita $\mathrm{Ceia}^{29}$ relata um estudo realizado há alguns anos, que demonstra o despreparo com as normas de cunho internacional, já que cita o trabalho desenvolvido por José Ricardo Cunha, entre os magistrados do Tribunal de Justiça do Estado do Rio de Janeiro, onde $84 \%$ dos juízes não tiveram qualquer formação em direitos humanos e 59\% deles declararam conhecer apenas superficialmente os sistemas da ONU e da OEA. Cita ainda a atuação do STF, que em diversos casos se vê diante da aplicação das normas da Convenção Americana de Direitos Humanos.

Ceia $^{30}$ relata que a jurisprudência da Corte nos julgados do STF ainda é modesto e que a falta de familiaridade com os tratados internacionais de direitos humanos representa um excesso de proteção à soberania nacional o que dificulta o cumprimento das sentenças da Corte. Aduz que incorporando esse tema aos trabalhos e rotinas dos agentes políticos brasileiros, será ainda mais fácil sua compreensão, aceitação e aplicação. Conclui ainda que:

O desenvolvimento da consciência acerca do direito internacional abarca diversas iniciativas, como a inclusão da disciplina de direitos humanos nos currículos dos programas de graduação e pós-graduação universitários, a inserção da matéria de direitos humanos no exame nacional para a $\mathrm{OAB}$, a inclusão da referida matéria nos concursos públicos para ingresso nas carreiras jurídicas - como para Delegado da Polícia Federal, Advogado-Geral da União e Defensor Público e programas de formação e capacitação em direitos humanos para integrantes dos três Poderes e das Forças Armadas. O fortalecimento da cultura dos direitos humanos é exigência usual nas sentenças da Corte em casos de condenação por violação de direitos humanos e, seguramente, evitaria os cenários de parcialidade e impunidade presentes, por exemplo, no caso Escher e outros vs. Brasil e no caso Garibaldi vs. Brasil. ${ }^{31}$

Assim, o investimento para ampliação do conhecimento sobre o tema aos agentes que lidam com questões práticas do direito internacional, bem como dos direitos humanos só contribuiria para melhor efetividade da sua aplicação.

\section{CONCLUSÃO}

Conclui-se portanto, que as decisões da Corte Interamericana de Direitos Humanos representam um significativo avanço no direito internacional brasileiro, vez que a aplicação das sentenças funciona como mecanismo regulador de aplicabilidade e efetividade dos direitos humanos no Estado brasileiro. 
Como demonstrado no presente trabalho, o Brasil e também outros países tem se adaptado a receber as regras de direito internacional, contudo, ainda que tenha havido progresso, esse não foi suficiente.

O Estado Brasileiro apresenta atualmente um índice altíssimo de casos de violação aos direitos humanos. Basta verificar as manchetes nos jornais.

Assim, ainda que casos polêmicos venham a plano, ou mesmo analisando os casos julgados pela Corte, percebe-se que sempre haverá violação de direitos já constituídos no mundo moderno. Entretanto, é importante ressaltar, que a postura que os organismos internacionais de proteção adotam para contribuir com a efetividade das normas, que promovem proteção aos indivíduos das barbáries cometidas em sociedade é de elevado valor.

Em busca da plena efetividade dos direitos humanos, vislumbra-se que a aceitação das normas humanísticas como fontes de direito constitucional e não somente compreendidas com status de supralegalidade, contribuiria para seu avanço, tendo em vista que garantindo sua obrigatoriedade e aplicação em todas as decisões, bem como permitindo seu conhecimento pelos agentes políticos e agentes que manipulam diariamente o direito, facilitaria a realização e efetividade das normas.

Busca-se também o cumprimento da obrigação do Estado de investigar, processar e punir penalmente qualquer responsável por violar os direitos humanos.

A Corte Interamericana e suas decisões representam o avanço e transformações jurídicas, legislativas, politicas e culturais no Brasil, o que promove o Estado Democrático de Direito, assim como a aplicação dos direitos humanos. As decisões da Corte delimitam como deve ser o agir do Estado em casos semelhantes, promovendo a conscientização das normas humanísticas no país.

Em casos atuais, percebe-se que grande parte da população se solidariza com os injustiçados, porém outra gama de pessoas critica veemente a atuação e aplicação de direitos humanos, já que possuem uma visão micro da sociedade, compreendendo-o apenas como sistema de proteção de minorias ou grupos isolados, por exemplo, mulheres, negros, homossexuais e etc. A partir dessa análise atual, compreende-se que se houvesse um estudo concreto dessa disciplina nas graduações, pós-graduações e também em diversos ramos da sociedade, a população entenderia que as normas humanísticas são para proteção do individuo, independente de suas condições físicas, psíquicas, econômicas, culturais, políticas ou filosóficas. Não há discriminação ou qualquer tipo de preconceito. Justamente, o zelo para aplicação desses direitos representa a máxima conquista da vida em sociedade e também o apelo para garantir ao ser humano uma vida digna, livre de barbáries e horrores de guerra, perseguições politicas, chacinas, mortes encomendadas, execuções extrajudiciais, desaparecimentos forçados e tantos outros crimes e atos de crueldade.

Realmente, somente a consagração das normas de proteção aos direitos humanos como instrumento constitucional na jurisprudência internacional, bem como a ampliação da cultura de direitos humanos no campo doméstico, além do profissional é que poderão permitir a aceitação e reconhecimento por parte da sociedade de que a proteção aos direitos humanísticos nada mais é do que a própria proteção da espécie humana contra atos de crueldade, que podem algumas vezes ser 
reconhecidos como legais, porém serão sempre ilegítimos.

\section{REFERÊNCIAS}

BRASIL. Constituição (1998). Constituição da República Federativa do Brasil. In: VADE mecum. 7. ed. São Paulo: Saraiva, 2015.

BRASIL. Decreto $n^{\circ}$ 678, de 6 de novembro de 1992. Promulga a Convenção Americana sobre Direitos Humanos (Pacto de São José da Costa Rica), de 22 de novembro de 1969. Brasília: Presidência da República do Brasil, 1992. Disponível em: http://www.planalto.gov.br/ccivil_03/ decreto/D0678.htm. Acesso em: 20 mar. 2018.

BRASIL. Supremo Tribunal Federal. Recurso Extraordinário nº 466.343. Recorrente: Banco Bradesco S/A. Recorrido: Luciano Cardoso Santos. Relator: Ministro Cezar Peluso, 3 de dezembro de 2008. Disponível em: http://redir.stf.jus.br/paginadorpub/paginador. jsp?docTP=AC\&docID=595444. Acesso em: 20 mar. 2018.

CEIA, Eleonora Mesquita. A jurisprudência da Corte Interamericana de Direitos Humanos e o desenvolvimento da proteção dos direitos humanos no Brasil. Revista Emerj, Rio de Janeiro, v. 16, n. 61, p. 113-152, jan./mar. 2013. Disponível em: http://www.emerj.tjrj.jus.br/revistaemerj_ online/edicoes/revista61/revista61_113.pdf. Acesso em: 5 dez. 2017.

COMISSÃO INTERAMERICANA DE DIREITOS HUMANOS. Caso Favela Nova Brasília Vs. Brasil. Interpretação da Sentença de Exceções Preliminares, Mérito, Reparações e Custas. Brasil, 5 de fevereiro de 2018. Serie $C \mathrm{~N}^{\mathrm{o}} .345$.

COMISSÃO INTERAMERICANA DE DIREITOS HUMANOS. Caso Gomes Lund e outros (“Guerrilha do Araguaia”) Vs. Brasil. Exceções Preliminares, Mérito, Reparações e Custas. Brasil, 24 de novembro de 2010. Serie C Nº 219.

COMISSÃO INTERAMERICANA DE DIREITOS HUMANOS. Caso Ximenes Lopes Vs. Brasil. Exceção Preliminar. Brasil, 30 de novembro de 2005. Serie C No. 139.

COMISSÃO INTERAMERICANA DE DIREITOS HUMANOS. Estatuto da Corte Interamericana de Direitos Humanos. La Paz: CIDH, 1989. Disponível em: https://cidh.oas.org/ Basicos/Portugues/v.Estatuto.Corte.htm. Acesso em: 20 mar. 2018.

COMISSÃO INTERAMERICANA DE DIREITOS HUMANOS. Relatório nº 141/11. Mérito. Caso 11.566 e 11.694. Mérito. Cosme Rosa Genoveva, Evandro de Oliveira e outros (Favela Nova Brasília), Brasil, 31 de outubro de 2011. Disponível em: https://sidh.cejil.org/es/document/ mdpk7vb6auugposd81knpnwmi. Acesso em: 20 mar. 2018.

COMISSÃO INTERAMERICANA DE DIREITOS HUMANOS. Relatório $n^{\circ}$ 91/08. Caso 11.552. Mérito. Julia Gomes Lund e outros (Guerrilha do Araguaia), Brasil, 31 de outubro de 2008.

CORREIA, Theresa Rachel Couto. Corte Interamericana de Direitos Humanos. Curitiba: Juruá Editora, 2008.

FERRAJOLI, Luigi. A soberania no mundo moderno: nascimento e crise do Estado nacional. 
São Paulo: Martins Fontes, 2002.

RIBEIRO, Lorena de Sá. Tratados internacionais sobre Direitos Humanos e seu status constitucional. Brasília, 2010. Disponível em: http://www.conteudojuridico.com.br/ artigo,tratados-internacionais-sobre-direitos-humanos-e-seu-status-constitucional,28863.html. Acesso em: 20 mar. 2018.

SARLET, Ingo Wolfgang. A eficácia dos direitos fundamentais. 6. ed. Porto Alegre: Livraria do Advogado, 2006.

Recebido em: 23/10/2019.

Aprovado em: 09/11/2019. 